\title{
The Effects of Open Captions in a Medical Drama on the Acquisition of Medical Terminology about Chronic Health Conditions Related to Physical Injury
}

\author{
Hyang-Sook Kim and Kyongseok Kim \\ Towson University
}

\begin{abstract}
Background: Despite previous efforts to improve health literacy through entertainment media, current practice seems to address only a few public health topics. Purpose: We examined the impact of supplementary open captions about medical terminology related to physical injuries that might lead to chronic health conditions on the acquisition and retention of relevant information presented in a medical drama. Methods: We conducted a two-group, betweensubjects experiment (no open captions vs. open captions) with 150 adult participants to measure how open captions might help viewers retain medical information without disrupting their enjoyment of the storyline. Results: The open captions helped viewers retain the terms and their definitions without disrupting narrative transportation to the events in the episode. Discussion: As long as the open-captioned medical information was seamlessly woven into the storyline of the episode, it did not prevent the viewers from appreciating the dramatic content of the show. Translation to Health Education Practice: Health educators are encouraged to collaborate with media producers to implement open captions for health and medical information rather than simply monitoring the accuracy of health and medical topics featured in television shows.
\end{abstract}

\section{Background}

Since the introduction of entertainment-education $(\mathrm{E}-\mathrm{E})^{1}$, scholars have investigated how entertainment media can be used as an educational tool, especially for health communication. ${ }^{2,3}$ Previous studies have explored the potential of E-E (i.e., "intentional placement of educational content in entertainment messages" to deliver the content in a less obtrusive manner ${ }^{4,5}$, p. ${ }^{117}$ ) as a vehicle of persuasion in communicating health-related issues, including cancer $^{6-8}$, human papillomavirus (HPV) ${ }^{9}$ and risky behaviors such as smoking, unsafe $\operatorname{sex}^{10}$, and binge drinking. ${ }^{11,12}$ The advantage of using E-E over traditional methods of persuasion, such as public service announcements (PSA), is that narratives invite people to engage in storylines with their favorite characters, lowering their doubt or suspicion about recommended behaviors and, hence, limiting reactance to the embedded messages. ${ }^{1,8,13}$

While research has demonstrated the effectiveness of E-E in persuading people to engage in healthy behaviors, ${ }^{3}$ a few studies have examined more specifically the potential of E-E to improve health literacy among the general public. Promotional health messages conveyed through entertainment content not only changed viewer perceptions but also increased knowledge about particular health topics. ${ }^{6}$ However, this line of research has emphasized the persuasive effects of E-E on attitudinal and behavioral change more than the direct potential of E-E to improve health literacy. In fact, medical drama viewers are continually exposed to a variety of medical settings. While used to enhance story realism, a number of unfamiliar medical terms are mentioned in dramatized medical settings, including operating and emergency rooms and doctor's offices along with a number of unfamiliar medical terms. Yet viewers are given few opportunities, often none, to obtain accurate, useful medical information from their viewing experience.

One way to demystify the perplexing world portrayed in medical dramas is to provide viewers with information about medical terms using open captions. Open captioning refers to "the use of captions on the screen which appear as part of the original broadcast and, thus, require no special equipment to receive or decode them." ${ }^{4(\mathrm{p} 9)}$ Although several PSAs and PBS programs have been produced with supplementary open captions, they are not frequently used in media production in the United States. ${ }^{14}$ At the same time, closed captions and subtitles, which are almost universally used in the industry ${ }^{15}$ and are similar in format to open captions, have been shown to facilitate the acquisition of educational content. ${ }^{16-20}$ Thus, the current study explored how open captions might increase public health literacy when used to supplement E-E. 


\section{Health literacy and entertainment education}

Health literacy is "the capacity to obtain, process, understand, and communicate about health-related information

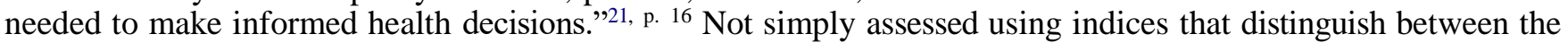
literate and illiterate audiences of health-related information, this definition of health literacy calls for comprehensive, often specialized measures of the ability to utilize available information to stay healthy. In other words, continuous knowledge acquisition is crucial to health literacy across a full range of topics. In this regard, statistics that indicate the overall improvement of health literacy among adults in the United States might not accurately represent health literacy across a wide spectrum of relevant health areas. ${ }^{22}$ In particular areas of health, such as cancer, diabetes, or medical terminology used in health care, a serious gap might exist between the actual knowledge of patients and the expectations of health professionals. ${ }^{23-25}$ Therefore, the health literacy needs of adults should be addressed in a continual and long-term manner.

One way to improve health literacy is to educate the general public about health issues using entertainment content. ${ }^{2}$ Previous studies have found that viewers of entertainment programs, compared to non-viewers, reported higher levels of awareness of health topics such as breast cancer screening ${ }^{6,8}$ and higher levels of knowledge about healthrelated issues such as $\mathrm{HVP}^{9}$ or the fatal consequences of binge drinking. ${ }^{11}$ Some of these studies have found that when viewers enjoyed a media experience (e.g., transportation through dramatized story), they retained more knowledge about the health topic depicted and reported preservation of the attitude and behavior promoted in the message as a result of long-term exposure. ${ }^{6,8}$

The transportation theory posits that viewers are likely to lose track of time when immersed in narratives in which characters they like come to life. ${ }^{26} \mathrm{~A}$ narrative is "any cohesive and coherent story with an identifiable beginning, middle, and end that provides information about scene, characters, and conflict; raises unanswered questions or unresolved conflict; and provides resolution." "(p778) Given concrete storylines and characters in a story, viewers can more easily concentrate on and enjoy narratives about topics of interest. Two prominent psychological outcomes of narrative immersion point to the mechanism behind entertainment content consumption: the absorption of narrative and identification with characters. ${ }^{8}$ Absorption is a state of total focus on a story in narrative form, ${ }^{27}$ whereas identification is a state of understanding and sympathizing with the characters in a story. ${ }^{28}$ Both states are components of narrative transportation and indicate the cognitive evaluation of and emotional connection to a fictional world. ${ }^{28,29}$

In the context of E-E, promotional messages should be seamlessly embedded in a narrative not only to facilitate immersion in the story but also to prolong the post-effects of a promotional message. ${ }^{7,8}$ For instance, Murphy et al. ${ }^{8}$ found that viewers reported a higher level of knowledge about the target health after watching an episode of Desperate Housewives $(\mathrm{ABC})$ in which one of the protagonists disclosed her cancer diagnosis to her friends. After watching the episode, viewers who were transported to the narrative reported higher levels of knowledge, more favorable attitude toward seeking out additional information about the health issue, and stronger information seeking behavior than viewers who were not. Although they did not directly investigate narrative transportation, Hether et al. ${ }^{6}$ and Markus et al. ${ }^{7}$ found that viewers who watched particular episodes about breast cancer from medical dramas such as ER (NBC) and Grey's Anatomy (ABC) reported greater levels of knowledge about the target health issue.

Other studies have suggested that medical dramas can enhance knowledge about various themes related to health communication. Hirt et al. ${ }^{30}$ analyzed 177 episodes of 8 popular medical dramas aired between 1990 and 2009 in order to concretize the potential of medical dramas to educate viewers about medical issues. Their analysis indicates that these medical dramas could be used as educational materials for various topics, including communication skills in health care settings, ethical concerns surrounding health practices, relationship management and professionalism among health professionals, and hospital environments.

\section{Captioning to improve learning from entertainment content}

Considering that continual acquisition of health-related knowledge is crucial to health literacy, ${ }^{12}$ occasional exposure to health topics addressed in medical dramas might not be sufficient to say that E-E can play a vital role in health literacy. ${ }^{7,8}$ Furthermore, the complexity of medical practices, coupled with arcane medical terms, could lead to arbitrary interpretations of particular scenes. ${ }^{31}$ This room for ambiguity surrounding medical terms and procedures could undermine the acquisition of medical knowledge from medical dramas. Therefore, viewers need a practical approach to help them achieve an accurate understanding of medical terms, for they are likely to gain medical knowledge to a certain degree simply by watching medical dramas over time. ${ }^{32}$

In this regard, studies about captioning and subtitling in media, including television and film, are relevant to the current study. The general perception about captions, particularly closed captions (i.e., viewers can choose to turn 
them on), is that some audiences need them to consume media that features spoken words (e.g., the hearing impaired). ${ }^{33}$ However, previous studies have shown that general audiences can still benefit from captions and subtitles. For instance, the addition of visual text on a screen to complement audible words can help with foreign language acquisition and increase retention of knowledge presented in educational materials. ${ }^{16-20}$ However, supplementary open captions to help medical drama viewers learn the meaning of medical terms associated with various topics (e.g., medical practices, drugs, health care system) are rare. In fact, currently available captioning methods usually complement the audible scripts and sound effects of media content. Thus, the current study proposed that open captions for medical terms that appear during relevant scenes of medical dramas might help viewers acquire medical knowledge as they consume entertainment content, optimizing the positive effects of E-E on health literacy.

\section{Implementation of open captions for medical terminology}

The key mechanism in learning through entertainment content is narrative transportation. Therefore, the impact that information supplied by open captions might have on the consumption of entertainment content needs clarification. In EE, most viewers consume narratives through visual and audio stimuli. ${ }^{4}$ Therefore, open captions for medical terms would provide an additional mode of communication (i.e., text) that viewers would need to coordinate during narrative transportation. As a result, viewers might allocate cognitive resources to separate but simultaneous tasks in order to consume both narrative content and informational text, potentially causing cognitive overload and impeding transportation.

The limited capacity model of mediated message processing (LCMP) can help explain this phenomenon. ${ }^{34}$ This theory posits that individuals allocate available but limited cognitive resources to information processing to a different degree during media consumption. The allocation of cognitive resources occurs in three areas of information processing: attending to (i.e., encoding), remembering (i.e., storage) and recalling (i.e., retrieval) the information during and after exposure to a certain amount of media content. First, people respond in different ways to information conveyed through media content depending on the amount of attention they give to particular segments of that information. This behavior is known as an orienting response (i.e., involuntary reflex caused by changes in environmental stimulation). ${ }^{34}$ Second, people store information at various levels depending on the amount of relevant knowledge that is immediately available after exposure to the content or that is already available in their memory ${ }^{34}$ Finally, the extent to which people can retrieve information depends on the amount of recollection that is required at the time of information storage. ${ }^{34}$ The typical retrieval of information requires a certain amount of recollection of memory available long after information was initially stored (i.e., later retrieval). However, the retrieval of relevant prior information might also occur while encoding and storing new information in order to make sense of it (i.e., concurrent retrieval). ${ }^{34}$

Lang $^{35}$ articulated the importance of motivational factors (e.g., personal relevance to information and the selection of communication modes to carry the information) to a modified LCMP, the limited capacity model of motivated mediated message processing (LC4MP). This later version posits that while the encoding, storage, and retrieval of information occur in a continuous and simultaneous fashion, one's interest in the information and the delivery method (e.g., audio, print, or video) can impact the allocation of cognitive resources to each area of information processing. ${ }^{35}$ For instance, when the information presented in media content is highly relevant (e.g., breast cancer topic depicted in an episode of a popular drama watched by women, such as Desperate Housewives ${ }^{8}$, viewers will pay attention to, remember, and recall health-related information better than when the information is less relevant. That is, relevance leads viewers to optimize the cognitive resources available to them while consuming the media content. In addition, information processing can also vary with communication mode type. Hybrid modes (e.g., multimodality central to television or new media) are more likely to lead to cognitive overload than a single mode (e.g., audio only). Therefore, television shows must stimulate the senses by "eliciting orienting responses using rapid scene changes, camera movement, and background sound" $35(\mathrm{p567)}$ in order to optimize the encoding and storage of information.

\section{Narrative transportation or cognitive overload?}

Based on the theoretical propositions of $\mathrm{LCMP}^{34}$ and LC4MP ${ }^{35}$, narratives in medical dramas should facilitate information encoding and storage if they feature stimulating elements (e.g., scenes of invasive surgery and brutal accidents) and/or familiar health topics (e.g., familiar medical cases frequently depicted in medical dramas). Therefore, the only difference between the presence and absence of open captions for medical terms should be the amount of cognitive resources required to process information shown in the captions. In fact, transportation is a process through which sensory and mental resources converge on events depicted in narratives. However, unlike cognitive evaluation, which requires people to use logical thought for judgment, transportation allows people to detach themselves from thought, driving them toward surreal experiences via narrative immersion. ${ }^{26}$ Therefore, narrative transportation is likely to be interrupted when cognition for additional information is momentarily and forcefully activated. In other words, an additional mode of communication (i.e., open captions for medical terms related to a scene) could result in cognitive 
overload, given the theoretical assumptions of LCMP and LC4MP..$^{34,35}$

Cognitive overload might not occur during narrative transportation, however. According to cognitive load theory, ${ }^{36}$ learning depends on the presence (or absence) of three types of cognitive load during working memory activation: intrinsic, extraneous, and germane. ${ }^{37}$ Intrinsic cognitive load occurs when a learner processes information presented in learning materials (i.e., cognitive load exclusively associated with content) and tries to recall relevant prior knowledge. Extraneous cognitive load results from distracting behaviors or a noisy environment (i.e., factors that are irrelevant to the learning process). Germane cognitive load is primarily determined by instructional design, which facilitates effective learning by optimizing the effect of intrinsic cognitive load on learning outcomes (e.g., pictorial information for preschoolers vs. text-based information for adults). Therefore, whether viewers experience cognitive overload is determined by how many cognitive resources they can allocate to the information delivered by media content. ${ }^{38}$

In other words, the processing of core content (e.g., narrative) will not be interrupted by additional information (e.g., open captions for medical terms) if the added element does not cause distraction through cognitive overload. Cierniak et al. ${ }^{38}$ examined the role of each type of cognitive load as participants learned about the physiology of kidneys through a computer screen. Their study compared the allocation of cognitive resources in relation to two different presentation formats - cohesive and integrated vs. scattered and unstructured - to determine whether the extraneous cognitive load used to make sense of the unstructured format would interrupt learning and the germane cognitive load permitted by the integrated format would transfer its positive effect on learning to the intrinsic cognitive load. They found that the integrated format (i.e., less distracting) yielded a higher level of knowledge acquisition.

Furthermore, distraction might not occur if the orientation of additional text-based information (i.e., open captions for medical terms) is consistent with the topic depicted in the story. For instance, Hawlitschek and Joeckel ${ }^{39}$ found that adding text instructions to educational video games enhanced recall and learning outcomes because the players could focus better on the content (i.e., germane cognitive load). Oviedo et al. ${ }^{40}$ also found that participants who simply watched the sitcom episodes reported a greater level of enjoyment and information recall than those who watched the episodes while engaged in other tasks irrelevant to the content (e.g., updating Facebook status, commenting, or liking the posts of other users).

Exploring the relationships among captioning, distraction, and learning performance, Kruger and Steyn ${ }^{17}$ found a positive correlation between subtitle reading (i.e., eye-tracking technique) and learning performance (i.e., secondlanguage speakers of English in South Africa. This finding indicates the effectiveness of dual coding (e.g., visual and verbal) when learning. In the same way, when medical drama viewers encounter no distraction when exposed to open captions for medical terms, they should remain immersed in the narrative while learning the terms.

\section{Purpose}

We investigated how supplementary open captions impact the acquisition of medical terminology in the context of E-E. Previous findings suggest two possible directions that viewer acquisition of medical terminology might take while watching a medical drama. ${ }^{34,35,38,40}$ On the one hand, viewers might experience cognitive overload when receiving content through multiple sensory channels (e.g., audio, visual, and textual). On the other hand, viewers might not experience cognitive overload if the educational information is congruent with the entertainment content. Therefore, we proposed that cognitive overload while processing the information supplied by open captions on the screen might prevent transportation into the narrative of a medical drama, limiting recall of the medical terminology due to lack of attention and recognition. However, when cognitive load is effectively allocated to the general viewing experience, preserving narrative transportation, viewers might retain the medical terminology presented during the episode. Therefore, we posited the following hypothesis:

Hypothesis: Viewers will report different levels of (a) knowledge retention of the medical terms, $(b)$ attention, $(c)$ recall of story depicted in the scenes, or $(d)$ narrative transportation depending on the presence (vs. absence) of open captions for medical terms used in the scenes of a medical drama episode.

\section{Methods}

The current study conducted an online experiment using a between-subjects design with two experimental conditions: (a) no open captions and (b) open captions for medical terms in an edited episode of a medical drama. A total of 202 adults residing in the United States were initially recruited using Amazon Mechanical Turk (MTurk), a popular 
crowdsourcing Internet marketplace for data collection in social science research. ${ }^{41}$ The final sample included 150 completed cases after dropping (a) 23 cases due to failure to meet the minimum requirement for participation time, 15 minutes (900 seconds) to complete the entire experimental task, and (b) 29 cases due to prior experience with the medical drama episode used in the experiment. After agreeing to participate for monetary compensation, participants were assigned to one of the two study conditions, watched a stimulus video (6 minutes in total), and answered a series of scale items for key variables. Participants also watched a 3-minute decoy video, which did not include open captions but provided a clue about the conclusion of the main story included in the main stimulus video, before responding to the knowledge retention measures. At the end of the study, participants responded to a health literacy instrument and demographic questions.

Over half $(52 \%)$ of the participants were female, and participant age ranged from 18 to 77 years $(M=38, S D=$ 11.73). Most of the participants were White (72\%), followed by Black (11\%), and Hispanic/Latino (7\%). In terms of education, $42 \%$ of participants had completed a Bachelor's degree, $21 \%$ had some college education, $13 \%$ had earned a Master's degree, and $10 \%$ had finished high school. General medical drama consumption level among the participants was fairly low $(M=2.85, S D=1.55$ on a 7-point scale), and their self-reported general health condition was considered overall good $(M=5.12, S D=1.27$ on a 7-point scale, $1=$ poor, $7=$ excellent $)$. The average duration time of study participation was 1,652 seconds, ranging from 901 seconds to 3,334 seconds $(S D=526$ seconds, $N=$ 150).

\section{Experimental stimuli}

In this study, we examined whether adding medical information in the form of open captions to medical-drama content might impact (i.e., disrupt or enhance) how the viewer experiences the narrative. Given the exploratory nature of this study, our stimulus was an edited version of the first episode of Grey's Anatomy from Season 13 ("Undo" aired on September 22, 2016) instead of an entire episode.

We edited the first 14 minutes of the episode down to a 6-minute video clip. We selected this portion of the episode based on the principles of LCMP. ${ }^{34}$ The video clip (a) contained stimulating but familiar scenes (i.e., physical fight between two male characters and subsequent hospital situations) that might facilitate narrative consumption and (b) addressed a neutral health topic, as opposed to a topic that a particular group of people (e.g., people with breast cancer or sexually transmitted diseases) is particularly motivated to learn about.

In the video clip used for the treatment condition, we embedded as text five medical terms and their brief definitions: zygomatic fracture, hyphema, etomidate, entrapment, and Lorazepam. We selected these five terms not only because they were relevant to the content of the video clip but also because the medical conditions (e.g., zygomatic fracture and hyphema) can have long-term impacts on health. For example, patients with zygomatic factures are likely to experience chronic tinnitus (i.e., a ringing, hissing, or booming sensation in one or both ears) ${ }^{42}$, and hyphema can result in permanent vision impairment when left untreated. ${ }^{43}$

We obtained definitions of the five terms from reliable sources (see Appendix 1). Each definition contained no more than 20 words and appeared on screen for 10 seconds. In Newman and Koskinen ${ }^{19}$, bilingual middle school students watched a captioned entertainment video for a science subject with a speed of 120 words per minute (i.e., 20 words every 10 seconds). Therefore, the duration was reasonable for adult English-speaking viewers. For the control condition, we presented an identical version of the video without open captions.

Finally, to allow participants time to process and store the health information they received from the stimulus video clip, we presented a three-minute decoy video clip (taken from the same episode used for the stimulus) to participants before they responded to the knowledge retention measures. Ostensibly unrelated to the purpose of this study, the video clip gave participants a clue about the conclusion of the entire episode to maintain their appreciation of the narrative in the stimulus video clip. ${ }^{12,34}$

\section{Dependent variables ${ }^{1}$}

\section{Attention}

Two self-reported attention scales ${ }^{44,45}$ were adapted for use in the current study. A total of eight items asked participants to rate their attention to elements in the video they watched, including aspects of the characters and information related to the medical events and procedures depicted in the video $(\alpha=.92 ; M=5.48, S D=1.20, N$ $=150)$.

\section{Episode content recall}

A cued recall measure was used to measure cognitive load when encoding and storing the narrative aspects of the 
video they watched. ${ }^{34,46}$ Three multiple-choice questions asked participants to select correct information about the storyline in the stimulus video ${ }^{46}$ The scores of the three questions $(0=$ incorrect $; 1=$ correct $)$ were summed to generate an index value $(M=2.26, S D=.91, N=150)$.

\section{Transportation}

Involvement with the narrative was measured using eleven modified items from the transportation scale. ${ }^{8,28}$ The items asked participants to rate the degree of their absorption in the storyline. Identification with characters was not measured in the current study because the length of the video might not have been sufficient to develop a genuine connection with the characters. ${ }^{47}$ One item was dropped due to relatively low reliability $(\alpha=.79)$. A total of 10 items were indexed based on good reliability of scale $(\alpha=.84 ; M=4.14, S D=1.78, \quad N=150)$.

\section{Knowledge retention}

Participants answered five multiple-choice questions that contained the definitions of the target medical terms presented in the stimulus video clip. ${ }^{7}$ The participants completed this portion of the questionnaire after watching the decoy video. All of the other dependent measure items (i.e., attention, content recall, and transportation) were completed before watching the decoy video. The scores of the five questions $(0=$ incorrect; $1=$ correct $)$ were summed to generate an index value $(M=3.03, S D=1.65, N=150)$.

\section{Control variables}

In order to control for each participant's general health literacy, we used a shortened version of the health literacy skills instrument from Bann, McCormack, Berkman and Squiers. ${ }^{48}$ This instrument was chosen from among a number of available health literacy scales because, first, it most adequately assesses the requirements that meet the definition of health literacy by Berkman et al. ${ }^{21}$ The instrument included 10 multiple-choice questions to test reading, interpretation, application, and health-related information seeking skills, primarily focusing on print literacy, numeracy, oral literacy and navigation proficiency. ${ }^{48}$ The scores of the items $(0=$ incorrect $; 1=$ correct $)$ were summed to generate an index value for health literacy $(M=6.25, S D=1.98, N=150){ }^{2}$

In addition, a shortened version of the Personal Involvement Scale ${ }^{49}$ was used (10 items on a 7-point scale; $\alpha=$ $.98 ; M=5.45, S D=1.27, N=150$ ) to control for involvement with the health topic (i.e., medical terminology used in health care settings). Involvement with the main story or information relevant to the story has been identified as a moderating factor in previous studies about E-E. ${ }^{50}$ Finally, participants were asked to rate their prior familiarity with the medical terms listed in the questionnaire, including the five terms used for the experiment, on a 7-point scale $(\alpha=.78, M=2.34, \mathrm{SD}=1.30, N=150)$. No difference in the three control variables was found between the two experimental conditions.

\section{Results}

To test the research hypotheses, a multivariate analysis of covariance (MANCOVA) was performed with the independent variable of video condition (no open captions vs. open captions). Issue involvement, prior familiarity with the medical terms, and health literacy were entered as covariates. The significant main effects of video condition on knowledge retention were found at both the multivariate (Wilks' $\lambda=.79, p<.001, \eta^{2}=.21$ ) and the univariate levels. Participants who watched the video with open captions recalled the medical terms better than those who watched the video without open captions $\left(M_{\text {open captions }}=3.72, S D=1.50, n=78 \quad\right.$ vs. $M_{\text {no open captions }}$ $\left.=2.28, S D=1.49, n=72 ; F_{[1,145]}=31.03, p<.001, \eta^{2}=.18\right)$. No statistical difference was found between the two video conditions for the other dependent measures (i.e., episode content recall, attention, and transportation). Overall, the results suggest that the inclusion of open captions might help viewers retain health knowledge without causing cognitive overload or interruption of transportation. Thus, hypothesis was partially supported by the data. Table 1 presents the MANCOVA results.

Additional analysis was conducted to confirm the positive impact of open captions on knowledge retention. Hierarchical regression was used to assess the relationship between the criterion variable (i.e., video condition: dummy coded as $1=$ open captions $v s$. $0=$ no open captions) and the outcome variable (i.e., knowledge retention) after accounting for variance associated with the control and mediator variables. The three control variables were entered in the first block of the model, the three mediators (i.e., episode content recall, attention, and transportation) in the second block, and the criterion variable in the third block. While controlling for known predictors (i.e., issue involvement, familiarity with the medical terms, and health literacy) and the mediators, the inclusion of open captions was positively associated with knowledge retention $(\beta=.39, t=5.68, p<.001)$. The analysis also confirmed that the amount of attention to the stimulus video and narrative transportation did not significantly 


\section{Discussion}

Despite demonstrating the positive influence of E-E on health literacy, ${ }^{6,8}$ scholars should continue exploring how content producers might use E-E more effectively to enhance health literacy in the long term. ${ }^{2}$ Using a two-group, post-test-only, between-subjects experimental design, the current study found that additional information about medical terms presented in the form of open captions increased knowledge acquisition. The effort required to process the information in the captions did not appear to disrupt narrative transportation. Concerning allocation of cognitive resources, participants in both conditions reported a similar level of attention to the narrative elements (i.e., storyline and characters) and the medical information presented in the video clip. Recognition of the storyline was also similar between the two conditions.

\section{Interdependent allocation of cognitive resources to retention and transportation}

The findings of the current study shed light on the possible interdependent activation of cognitive load for processing narrative elements and informational captions. The types of cognitive load used to learn might be different from those used to enjoy narratives. Although narrative transportation still involves cognitive evaluation of storylines and characters, along with the viewer's emotional responses, ${ }^{26}$ the cognitive resources used to become immersed in a narrative might not be conducive to anticipating clear learning outcomes. However, the working memory used to understand a story and the situations that characters encounter in a story (i.e., intrinsic cognitive load) is hardly separable from the working memory used to make sense of the medical terms used by the characters. The inherent link between the medical terms and their definitions provided in the open captions and the story that the participants processed could have facilitated both germane and intrinsic load while ruling out the possibility of extrinsic load, yielding higher retention of the medical terms mentioned in the entertainment content. ${ }^{38,39}$

Related to this finding, dual-coding theory ${ }^{51}$ posits that verbal information and nonverbal information are processed in separate but interdependent ways. The impact of coding is likely to be stronger when both coding modes are available. In the context of product placement, Jensen, Walsh, Cobbs and Turner ${ }^{52}$ examined the effects of brand integration (i.e., prominent vs. camouflaged) on brand recall and recognition in sport broadcasts. They found that brand integration that facilitated both modes of coding (i.e., audiovisual) yielded stronger effects than brand integration using a single mode (i.e., audio-only or visual-only). However, the distraction created by the additional screen negatively influenced brand recognition and brand recall.

Table 1. Descriptive statistics of dependent variables.

\begin{tabular}{lllrl} 
& $\begin{array}{c}\text { No Open } \\
\text { Captions } \\
(n=72)\end{array}$ & $\begin{array}{c}\text { Open } \\
\text { Captions } \\
(n=78)\end{array}$ & $\begin{array}{c}F \\
(p \text {-value })\end{array}$ & $\eta^{2}$ \\
\hline Knowledge retention & $2.28(1.48)$ & $3.72(1.50)$ & $31.03(.000)$ & .176 \\
Attention & $5.33(1.23)$ & $5.61(1.14)$ & $.76(.39)$ & .005 \\
Episode content recall & $2.24(.97)$ & $2.28(.85)$ & $.06(.81)$ & .000 \\
Transportation & $4.18(1.17)$ & $4.11(1.18)$ & $1.28(.26)$ & .009 \\
$\quad$ (absorption to & & & & \\
$\quad$ narratives) & & & &
\end{tabular}

Wilks' $\lambda=.79, p<.001, \eta^{2}=.21$. Means are reported in the condition columns with standard deviations in parentheses.

Table 2. Results of hierarchical regression (dependent variable: knowledge retention).

\begin{tabular}{|c|c|c|c|c|}
\hline Model & Predictor & $\beta$ & $t$ & $p$ \\
\hline \multirow{4}{*}{1} & Issue involvement & .22 & 2.88 & .005 \\
\hline & Familiarity with the medical terms & .12 & 1.53 & .127 \\
\hline & Health literacy & .28 & 3.69 & .000 \\
\hline & $R^{2}$ & .15 & & \\
\hline \multirow[t]{4}{*}{2} & Episode content recall & .24 & 2.98 & .003 \\
\hline & Attention & .06 & .57 & .572 \\
\hline & Transportation & -.13 & -1.35 & .181 \\
\hline & $R^{2}+1$ & .19 & & \\
\hline \multirow[t]{2}{*}{3} & Video condition (Open captions vs. No open captions) & .39 & 5.68 & .000 \\
\hline & $R^{2}$ & .34 & & \\
\hline
\end{tabular}




\section{Importance of consistency in entertainment content consumption}

The only difference between the two experimental conditions was the presence of open captions for medical terms and their definitions. Participants retained the information presented in the open captions, and indicators of cognitive load (i.e., content recall) and narrative immersion (i.e., transportation), along with attention to narrative content and medical knowledge in the clip, were similar in both conditions. In other words, the content in both experimental conditions was essentially consistent. The open captions contained terms that were relevant to the events depicted in the scenes, and the additional information complemented the narrative experience of the viewer.

According to LC4MP, ${ }^{35}$ media content can naturally stimulate viewers to pay attention to content and facilitate information storage by minimizing interruption of the viewing experience, improving information retrieval. This appetitive activation of motivation is expected unless the media content presents information that is perceived as threatening (e.g., information about the severe health consequences of a disease); in that case, viewers might intentionally divert their attention to peripheral information in the media content, a psychological defense mechanism that can prevent allocation of cognitive resources to process health information (i.e., aversive activation of motivation). ${ }^{35(\mathrm{pp} 561-562)}$

Viewers who watched the clip with open captions demonstrated better retention of the medical terms and their definitions. At the same time, this group maintained the same level of attention to core content as the control group, recalling narrative elements and reporting narrative immersion. This finding suggests that the open-captions group was not intimidated by the medical terms. Rather, the captions led to an appetitive activation of motivation to process the information in the video clip. This finding is also consistent with the positive correlation between reading captions and language learning performance when consuming media content (i.e., lecture) and subtitles that deliver identical information. ${ }^{17}$

\section{Limitations and future research}

The current study did not measure the enjoyment or gratification of the viewers when exposed to the entertainment stimulus because the screening time was too short. As a result, the theoretical connection between exposure to additional medical knowledge by reading open captions across an entire episode of a medical drama and the gratifying experience of narrative transportation remains unknown. Furthermore, emotions could impact the operation of cognitive load when processing information through open captions and following narrative events simultaneously. ${ }^{26,35}$

Moreover, the findings of the current study lack external validity because the experiment was conducted in a crosssectional manner (i.e., using a short video clip instead of a series of episodes of a medical drama). Shen and $\mathrm{Han}^{3}$ found that field experiments and longitudinal E-E studies (i.e., exposure to multiple episodes) generated larger effect sizes than laboratory experiments or single exposure studies. This limitation of the current study invites further investigation. In order to outline the full theoretical framework of narrative consumption with supplemental medical knowledge delivered by open captions, researchers need to measure emotional responses to narratives, transportation states, enjoyment, and gratification using full-length medical drama episodes.

Finally, a text-only condition was not included in our experiment to rule out the sheer effect of additional information on knowledge retention. However, the primary focus of the current study was (a) to test whether the addition of medical knowledge in the form of open captions might disrupt narrative transportation or enhance health literacy by complementing the narrative transportation effect of E-E and (b) to articulate the impact of open captions on cognitive load when processing entertainment media content.

\section{Translation to Health Education Practice}

Previous findings suggest that the applications of E-E are diverse, from addressing health topics to targeting consumers. ${ }^{2,15,53}$ Substantial amounts of entertainment content depict all kinds of health topics, including public health (e.g., nutrition, physical activity, smoking, and alcoholism), safe/unsafe sexual activities, medical treatments, mental illnesses, and addiction problems. ${ }^{53}$ In addition, as closed captioning in media production benefits various audiences of entertainment content (e.g., the hearing impaired, the elderly with hearing aids, non-native speaking audiences, and students in a wide range of educational settings ${ }^{15}$, open captioning should help promote health literacy and positive educational outcomes. Related to the implementation of open captions for health topic delivery (i.e., cervical cancer), a longitudinal study of 130 hearing-impaired women revealed that educational videos featuring medical information about cervical cancer in the form of open captioned American Sign Language enhanced retention of that information. ${ }^{54}$ 
Given the potential universal benefits of open captioning in E-E, our findings are encouraging. We found that the open captions for medical terminology embedded in an episode of a popular medial drama helped viewers acquire and retain medical information while still being as absorbed in the storyline as those who watched the episode without open captions. More importantly, as previous findings suggest, ${ }^{17,38}$ the positive effects of open captioning on medical information acquisition, without interrupting the narrative experience, occurred because seamless presentation of the storyline and open captions required little cognitive load to process.

Therefore, our findings strongly suggest that health educators should confidently work with media producers to implement open captions for health and medical information. Ideally, health educators and media producers should collaborate in the early stages of production (e.g., script writing or scene editing) to make sure the medical information featured in the open captions is integral to the storyline, minimizing disruption of viewer enjoyment. Although Turow argued that storylines in medical dramas exerted a significant influence on public perceptions of socially important topics (e.g., health care systems) even before the introduction of E-E, the industry has neglected the critical role that those storylines might play in health education. ${ }^{55}$ Therefore, health educators and policy makers should help establish a better standard of media production for health-related topics. Ultimately, barring implementation that confuses or frustrates the public in its consumption of entertainment content, using open captions to present medical information could improve the reach and longterm effectiveness of E-E in health education.

Notes

1. All of the measurement items are available in Appendix 2.

2. The instrument items are not listed in the Appendix due to licensing. The instrument was obtained after submitting the end-user agreement to Healthwise ${ }^{\circledR}$ at RTI International (https://www.rti.org/impact/healthliteracy-skills-instrument).

\section{Disclosure statement}

No potential conflict of interest was reported by the authors.

\section{References}

1. Singhal A, Rogers EM. Entertainment-Education: A Communication Strategy for Social Change. Mahwah, NJ: Lawrence Erlbaum Associates; 1999.

2. Kato M, Ishikawa H, Okuhara T, Okada M, Kiuchi T. Mapping research on health topics presented in primetime TV dramas in "developed" countries: a literature review. Cogent Soc Sci. 2017;3:1-16.

3. Shen F, Han J. Effectiveness of entertainment education in communication health informatión. Asian J Commun. 2014;24(6):605-616. doi:10.1080/01292986.2014.927895.

4. Hinyard LJ, Kreuter MW. Using narrative communication as a tool for health behavior change: a conceptual, theoretical, and empirical overview. Heal Educ Behav. 2007;34(5):777-792. doi:10.1177/1090198106291963.

5. Singhal A, Rogers EM. A theoretical agenda for entertainment-education. Commun Theory. 2002;12:117-135.

6. Hether HJ, Huang GC, Beck V, Murphy ST, Valente TW. Entertainment-education in a media-saturated environment: examining the impact of single and multiple exposures to breast cancer storylines on two popular medical dramas. J Health Commun. 2008;13 (8):808-823. doi:10.1080/10810730802487471.

7. Marcus PM, Huang GC, Beck V, Miller MJ. The impact of a primetime cancer storyline: from individual knowledge and behavioral intentions to policy-level changes. J Cancer Educ. 2010;25(4):484-489. doi:10.1007/s13187-010-0093-y.

8. Murphy ST, Frank LB, Moran MB, Patnoe-Woodley P. Involved, transported, or emotional? Exploring the determinants of change in knowledge, attitudes, and behavior in Entertainment-Education. J Commun. 2011;61:407-431.

9. Brodie M, Foehr U, Rideout V, et al. Communicating health information through the entertainment media. Health Aff. 2003;20(1):192-199.

10. Asbeek Brusse ED, Fransen ML, Smit EG. Educational storylines in entertainment television: audience reactions toward persuasive strategies in medical dramas. J Health Commun. 2015;20(4):396-405. doi:10.1080/ 10810730.2014.965365.

11. Bavin LM, Owens RG. Impact of an alcohol poisoning storyline in a fictional television program: an experimental study with a live-to-air stimulus. Health Commun. 2016;31:1258-1265.

12. Kim K, Lee M, Macias W. An alcohol message beneath the surface of ER: how implicit memory influences 
viewers health attitudes and intentions using entertainment-education. J Health Commun. 2014;19(8):876892. doi:10.1080/10810730.2013.837556.

13. Moyer-Gusé E. Preference for television programs about sexual risk: the role of program genre and perceived message intent. Media Psychol. 2010;13(2):180- 199. doi:10.1080/15213261003800751.

14. Garza TJ. The message is the medium: using video materials to facilitate foreign language performance. Texas Pap Foreign Lang Educ. 1996;2:3-20.

15. Gernsbacher MA. Video captions benefit everyone. Pol Ins Behav Brain Sci. 2015;2:195-202.

16. Birulés-Muntané J, Soto-Faraco S. Watching subtitled films can help learning foreign languages. PLoS One. 2016;11(6):1-11. doi:10.1371/journal.pone.0158409.

17. Kruger JL, Steyn F. Subtitles and eye tracking: reading and performance. Read Res Q . 2014;49(1):105-120. doi:10.1002/rrq.59.

18. Lavaur J-M, Bairstow D. Languages on the screen: is film comprehension related to the viewers' fluency level and to the language in the subtitles? Int J Psychol. 2011;46 (6):455-462. doi:10.1080/00207594.2011.565343.

19. Newman SB, Koskinen P. Captioned television as comprehensible input: effects of incidental word learning from context for language minority students. Read Res Q. 1992;27(1):94-106. doi:10.2307/747835.

20. Parkhill F, Davey R. We enjoyed it and we learned at the same time! Pract Prim. 2012;17:8-12.

21. Berkman ND, Davis TC, McCormack L. Health literacy: what is it? J Health Commun. 2010;15(suppl 2:9-19. doi:10.1080/10810730.2010.499985.

22. Paasche-Orlow MK, Parker RM, Gazmararian JA, Nielsen-Bohlman LT, Rudd RR. The prevalence of limited health literacy. J Gen Intern Med. 2005;20 (2):175-184. doi:10.1111/j.1525-1497.2005.40245.x.

23. Castro CM, Wilson C, Wang F, Schillinger D. Babel babble - physicians' use of unclarified medical jargon. Am J Health Behav. 2007;31(Suppl 1):S85-S95. doi:10.5555/ajhb.2007.31.supp.S85.

24. Chapman K, Abraham C, Jenkins V, Fallowfield L. Lay understanding of terms used in cancer consultations. Psychooncology. 2003;12:557-566. doi:10.1002/pon.673.

25. Hadlow J, Pitts M. The understandings of common health terms by doctors, nurses and patients. Soc Sci Med. 1991;32:193-196.

26. Green MC, Brock TC. The role of transportation in the persuasiveness of public narratives. J Pers Soc Psychol. 2000;79:701-721.

27. Csikszentmihalyi M. Flow: The Psychology of Optimal Experience. New York, NY: Harper \& Row; 1990.

28. Green MC, Brock TC, Kaufman GF. Understanding media enjoyment: the role of transportation into narrative worlds. Commun Theory. 2004;14(4):311-327. doi:10.1111/comt.2004.14.issue-4.

29. Bartsch A, Hartmann T. The role of cognitive and affective challenge in entertainment experience. Communic Res. 2017;44(1):29-53. doi:10.1177/0093650214565921.

30. Hirt C, Wong K, Erichsen S, White JS. Medical dramas on television: a brief guide for educators. Med Teach. 2013;35(3):237-242. doi:10.3109/0142159X.2012.737960.

31. Collee J. Medical fiction: should be accurate, but need not be didactic. Br Med J. 2011;318(7189):955-956. doi:10.1136/bmj.318.7189.955.

32. O'Connor S, Deeks JJ, Hawton K, et al. Effects of a drug overdose in a television drama on knowledge of specific dangers of self poisoning: population based surveys. Br Med J. 1999;318(7189):978-979.

33. NaseriBooriAbadi T, Sadoughi F, Sheikhtaheri A. Improving cancer literacy for the deaf using deaf-tailored educational interventions: a review of the literature. J Cancer Educ. 2018;33(4):737-748. doi:10.1007/ s13187-017-1216-5.

34. Lang A. The limited capacity model of motivated mediated message processing. J Commun. 2000;50 (2):4670. doi:10.1111/j.1460-2466.2000.tb02833.x.

35. Lang A. Using the limited capacity model of motivated mediated message processing to design effective cancer communication messages. J Commun. 2006;56:S57-80. doi:10.1111/j.1460-2466.2006.00283.x.

36. Paas FGWC. Training strategies for attaining transfer of problem-solving skill in statistics: a cognitive-load approach. J Educ Psychol. 1992;84:429-434.

37. Sweller J. Implications of cognitive load theory for multimedia learning. In: Mayer RE, ed. The Cambridge Handbook of Multimedia Learning. New York, NY: Cambridge University Press; 2005:19-30.

38. Cierniak G, Scheiter K, Gerjets P. Explaining the split-attention effect: is the reduction of extraneous cognitive load accompanied by an increase in germane cognitive load? Comput Human Behav. 2009;25 (2):315-324. doi:10.1016/j.chb.2008.12.020.

39. Hawlitschek A, Joeckel S. Increasing the effectiveness of digital educational games: the effects of a learning instruction on students' learning, motivation and cognitive load. Comput Human Behav. 2017;72:79-86. doi:10.1016/j.chb.2017.01.040.

40. Oviedo V, Tornquist M, Cameron T, Chiappe D. Effects of media multi-tasking with Facebook on the enjoyment and encoding of TV episodes. Comput Human Behav. 2015;51:407-417. doi:10.1016/j. chb.2015.05.022.

41. Amazon. Amazon mechanical turk (MTurk): access a global, on-demand, $24 \times 7$ workforce. https://www. mturk.com/. Published 2019. Accessed March 1, 2019.

42. Yang -C-C, Tai C-J, Chien S-H, et al. Risk of ear-associated diseases after zygomaticomaxillary complex fracture. J Maxillofac Oral Surg. 2015;14:646-652. doi:10.1007/s12663-015-0744-y.

43. Turbert D What is hyphema? https://www.aao.org/eye-health/diseases/what-is-hyphema. Published 2018. Accessed April 2, 2019. 
44. Lee TK, Taylor LD. The motives for and consequences of viewing television medical dramas. Health Commun. 2014;29(1):13-22. doi:10.1080/10410236.2012.714346.

45. Rouner D. Active television viewing and the cultivation hypothesis. $J Q$. 1984;61:168-174.

46. Cooper CP, Roter DL, Langlieb AM. Using entertainment television to build a context for prevention news stories. Prev Med. 2000;31:225-231. doi:10.1006/ pmed.2000.0706.

47. Cohen J. Defining identification. Mass Commun Soc. 2001;4(3):245-264. doi:10.1207/S15327825MCS0403_01.

48. Bann CM, McCormack LA, Berkman ND, Squiers LB. The health literacy skills instrument: a 10-item short form. J Health Commun. 2012;17(SUPPL 3):191-202. doi:10.1080/10810730.2012.718042.

49. Zaichkowsky JL. Measuring the involvement construct. J Advert. 1985;12:341-352.

50. Alvarado M, Maskiewicz AC. Teaching high school physiology using a popular TV medical drama. Am Biol Teach. 2011;73(6):322-328. doi:10.1525/abt.2011.73.6.4.

51. Paivio A. Mental Representations: A Dual Coding Approach. New York, NY: Oxford University Press; 1986.

52. Jensen JA, Walsh P, Cobbs J, Turner BA. The effects of second screen use on sponsor brand awareness: a dual coding theory perspective. J Consum Mark. 2015;32:71-84.

53. Byrd-Bredbenner C, Finckenor M, Grasso D. Health related content in prime-time television programming. J Health Commun. 2003;8:329-341. doi:10.1080/ 10810730305721.

54. Choe S, Lim S-HR, Clark K, Wang R, Branz P, Sadler GR. The impact of cervical cancer education for deaf women using a video educational tool employing American Sign Language, open captioning, and graphics. J Cancer Educ. 2009;24(1):10-15. doi:10.1080/ 08858190802665245.

55. Turow J. Television entertainment and the US healthcare debate. Lancet. 1996;347(9010):1240-1243. doi:10.1016/s0140-6736(96)90747-3.

\section{Appendix 1: Medical terms and definitions}

Zygomatic fracture: this is most commonly seen after assault, but any blow to the cheek may give rise to a fracture (https:// www.ncbi.nlm.nih.gov/pmc/articles/PMC2658189/)

Hyphema: a hyphema is a pooling or collection of blood inside the anterior chamber of the eye (http://www.healthline. com/health/hyphema)

Etomidate: inducing general anesthesia and with other medications to provide anesthesia during short surgeries (https://www.drugs.com/cdi/etomidate.html)

Entrapment: a nerve compression of a nerve or vessel by adjacent tissue (http://medicaldictionary.thefreedictionary. com/entrapment)

Lorazepam: a group of drugs called benzodiazepines. It affects chemicals in the brain that may be unbalanced in people with anxiety (https://www.drugs.com/lorazepam.html).

\section{Appendix 2: Measures}

\section{Involvement with medical terms ${ }^{49}$}

Please indicate your impressions on "medical terms" that doctors use in the hospital setting. Make each item a separate and independent judgment. Work at fairly high speed through this portion of the questionnaire. Do not worry or puzzle over individual items. It is your first impressions, the immediate feelings about the items, that we want. On the other hand, please do not be careless, because we want your true impressions. $(1=$ Not at all, $7=$ Very much likely; $*$ indicates item is reverse scored.)

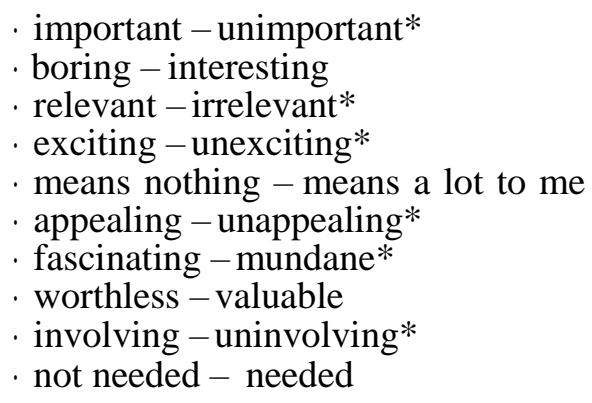

Attention to content $t^{44,45}$

Please indicate the number that best reflects the extent to which you agree or disagree with (1 being strongly 
disagree; 7 being strongly agree):

I was attentive to:

- the personal qualities of the characters;

- the characters' appearance;

- the values and morals displayed by the characters;

- the storyline;

- the medical information presented in the clip;

- the medical practice displayed in the clip;

- the diseases/injuries depicted in the clip;

- the medication or treatment presented in the clip.

Episode content recall (cued recall) $)^{46}$

(The three choices in each multiple-choice item, except for option "d," were randomized in the questionnaire for each participant)

Please select the best answer to each of the following questions about the story in the clip that you just watched.

(1). Alex (Karev, the male protagonist's name in the story of the clip you just watched) came to the hospital with
a. her girlfriend
b. the victim he assaulted (Correct answer)
c. Meredith from the wedding reception
d. Don't know

(2). Meredith (Grey, the female protagonist in the story) was trying to
a. turn in Alex to Bailey and the police
b. protect Alex from being caught by others (Correct answer)
c. ignore her and her friends' personal issues
d. Don't know

(3). The victim (Andrew Deluca) in the story had a severe injury on
a. his face (Correct answer)
b. his legs
c. his abdomen
d. Don't know

Transportation (Absorption to narratives) ${ }^{8,26}$

(* indicates the item excluded from the final index of scale)

Please indicate the number that best reflects your agreement or disagreement on each of the following statements ( 1 being strongly disagree; 7 being strongly agree):

- While I was watching the clip, I could easily picture the events in it taking place.

- While I was watching the clip, activity going on in the room around me was on my mind. (R)*

- I could picture myself in the scene of the events described in the clip I just watched.

- I was mentally involved in the story while watching the clip.

- After finishing the clip, I found it easy to put it out of my mind. (R)

- I wanted to learn how the entire episode of clip ended.

- The story affected me emotionally.

- I found myself thinking of ways the narrative could have turned out differently.

- I found my mind wandering while watching the clip. (R)

- The events in the story depicted in the clip that I just watched are relevant to my everyday life.

. The events in the story depicted in the clip that I just watched have changed my life.

\section{Knowledge retention ${ }^{7}$}

We are interested in how much you learn from the portion of drama you just watched in the study. PLEASE DO NOT GOOGLE THE TERMS IN THE QUESTIONS BELOW.

(The three terms in each multiple-choice item, except for option "d." were randomized in the questionnaire for each participant) 
(1). is commonly seen after assault, but also any blow to the cheek may give rise to a fracture.
a. Zygomatic fracture
b. Skull fracture
c. Enthlasis
d. Don't know

(2). A pooling or collection of blood inside the anterior chamber of the eye is called:
a. Transfusion
b. Coagulation
c. Hyphema
d. Don't know

(3). This typically induces general anesthesia and with other medications to provide anesthesia during short surgeries.
a. Paralysis
b. Etomidate
c. Aortic insufficiency
d. Don't know

(4). refers to a nerve compression of a nerve or vessel by adjacent tissue.
a. Entrapment
b. Cardiac insufficiency
c. Angina
d. Don't know

(5). A group of drugs which affects chemicals in the brain that may be unbalanced in people with anxiety is called:
a. Neurasthenia
b. Lorazepam
c. Cerebral infarction
d. Don't know

Prior familiarity with medical terms

(All of the terms were randomized when listed in the questionnaire for each participant)

How familiar were you with each of the following medical terms before participating this study? $(1=\mathrm{Never}$ heard of, 7 = Very familiar)

Hyphema; Etomidate; Entrapment; Lorazepam; Zygomatic fracture; Neurasthenia; Cerebral infarction; Cardiac insufficiency; Angina; Paralysis; Aortic insufficiency; Transfusion Coagulation; Skull fracture; Enthlasis. 